\title{
Casting Long-Term and Regenerative Perspectives on Global Sustainability through Systems and Resilience Thinking
}

\author{
Fabricio Casarejos ${ }^{1,2}$ \\ 1 Interdisciplinarity Center for the Unknown (ICU)-Fostering Global Sustainability through Imagination and \\ Futures Studies, Fama, Minas Gerais 37144-000, Brazil; casarejos@icunknown.com or \\ fabricio.casarejos@unifal-mg.edu.br \\ 2 Graduate Program in Governance and Society, Federal University of Alfenas (PPGPS/UNIFAL-MG), \\ Varginha Campus, Varginha, Minas Gerais 37048-395, Brazil
}

Received: 17 January 2020; Accepted: 6 February 2020; Published: 8 February 2020

\begin{abstract}
The main objective of this work is to foster long-term and regenerative perspectives on global sustainability. In pursuing this goal, this study encompasses a critical analysis and synthesis of insights from the fields of systems and resilience thinking, a conceptual framework for modeling and envisioning socio-ecological systems, and the proposition of the "flourishing within boundaries" archetype, which is conceived to provide meaningful insights regarding the essential conditions that would enable global society to flourish not just safely but also fairly. Through systems dynamics modeling, portrayed scenarios emphasize that the higher the regenerative societal change achieved, the greater the exponential behavior of the system's speed towards promising socio-ecological outcomes. Especially for longer time horizons, the overall results reveal that the pace of the transitions associated with the societal action is inherently higher than those associated with the limiting social and ecological factors. Actions taken by individuals in the local realm and short-term time horizon may not only have immediate local effects but also a variety of innumerous ones that radiate out for years, decades, and even centuries to come. Finally, the pursuit of flourishing within boundaries relies on thinking rationally, globally, and above all, through a long-term and regenerative perspective.
\end{abstract}

Keywords: sustainability; systems thinking; resilience; futures studies; sustainable development; planetary boundaries

\section{Introduction}

Western societies have benefited from reductionist thinking in science over complex one, especially with regard to the emphasis on the Cartesian and Newtonian analysis and its mechanistic understanding of nature [1,2]. Industrialized societies have been trained to break objects into small and comprehensible constituents, to trace direct paths from cause to effect, and to pursue solutions by predicting futures through controlling problems' causes [1-3]. Since the great acceleration of the mid-twentieth century, scientific developments have enhanced technology, production, infrastructure, patterns of comfort, and life expectancy [4-6].

While useful, reductionistic thinking is far from sufficient for the development of a complete set of knowledge and skills required to become effective in addressing complex problems $[1,2,7,8]$. Particularly, many essential issues of global sustainability (e.g., climate change, pollution, biodiversity loss, freshwater scarcity, disruptive land-system change, disease epidemics, hunger, poverty, lack of education, social and gender inequality, social conflicts, and warfare) have remained persistently unsolved [5,6,9-17]. Reductionist thinking is mostly inclined to model the world in terms of linear relations and single causes producing single effects, examining one or at most a few things at 
a time, and overlooking interdependencies, delays, and boundaries $[1,2,18]$. Nonlinearities and self-organization are often sacrificed for short-term productivity, stability, and predictability [2]. However, many relationships in systems are clearly nonlinear, and many causes come together to produce a myriad of interwoven effects [2,3,19-21]. Nonlinearities regulate a system's functionality, alter the dominance of interconnections within the system, and shift the system's behavior from one mode to another [21].

Sustainability issues are subjects of extraordinary interrelatedness and interdependence that arise out of complex interactions between human beings, their societal beliefs and structures, the physical world, and the economy $[2,4,9,18,21,22]$. In sustainability science, systems are examined as biogeophysical entities of coupled socio-ecological systems, emphasizing that human society must be seen as a part of, not apart from, nature [9-12,18,21,23]. Socio-ecological systems are self-organizing systems structured in non-linear feedback loops, inherently not divisible, and not deterministically controllable [3,21,22].

Systems and resilience thinking embrace change, uncertainty, unknowability, and normativity, enabling the examination of socio-ecological systems under the influence of a range of different intertwined driving factors and conditions [24-26]. They counteract bounded rationality that drives conclusions and actions that are not reasonable within broader contexts and time horizons [2]. They also reclaim the natural synergy between intuition and rationality, enhancing abilities to acknowledge complexity, be imaginative, and artfully inquire "why" and "what if" [2,24]. Particularly, why does human society continue to exhibit so little achievement in addressing the essential issues of global sustainability? What if these issues are not the main triggers, but merely the symptoms of humans' endeavor to maintain a non-regenerative physical growth in a finite planet with critical biogeophysical thresholds? [4,5,9-12,27]. What if the prevailing ways of thinking, communicating, learning, sense-making, and acting are ineffective and outdated, resulting in worsening global "problématique"? What if the main problem lies in ingrained social values, perspectives, and habits that deter regenerative changes at both individual and collective levels?

An imperative challenge of the 21st century is how global society will ensure that no one falls short on life's essentials needs (the fairness condition) while ensuring that human activities do not collapse the Earth's life-giving systems (the safeness condition)? To move forward, it is necessary to think synthetically as well as analytically, casting broadly while drilling deeply into detail. It is crucial to nurture transformative and regenerative ways of thinking and acting, yielding alternative narratives and enduring solutions that are simply not achievable within the same societal beliefs and structures that created the problems in the first place. In this regard, the main objective of this conceptual work is to foster long-term and regenerative perspectives on global sustainability. In pursuing this goal, this study is structured in three complementary research strands as follows: (i) A critical analysis and synthesis of insights from the fields of systems and resilience thinking, (ii) a conceptual framework for modeling and envisioning socio-ecological systems and their patterns of behavior over time, and (iii) the proposition of the "flourishing within boundaries" archetype, which is conceived to provide meaningful insights regarding the essential conditions that would enable global society to flourish not just safely but also fairly.

\section{Materials and Methods}

Approach formulation and assumptions: Bibliographic research was conducted focusing on transdisciplinary discussions aimed at fostering a flourishing society vis-à-vis the long-term challenges posed by global sustainability. Key concepts, issues, thematic similarities, and trends, as well as innovative and regenerative outlooks were identified and processed to substantiate and design this study as a whole. In light of a critical analysis and synthesis of insights from the fields of systems and resilience thinking, a conceptual framework (discussed in Section 3.1) was conceived as a guiding tool for modeling and envisioning socio-ecological systems within broad time horizons spatial realms. Taking into consideration the Sustainable Development Goals [6] and Planetary Boundaries [9-12], 
a systems dynamics archetype referred to as "flourishing within boundaries" (depicted in Figure 3) was conceived to provide meaningful insights regarding the essential conditions that would enable global society to flourish not just safely but also fairly.

Scenarios examination and assumptions: Scenarios are understood as plausible and rich narratives (portrayed in key concepts and mathematical parameters and functions) about systems evolutionary pathways and their essential contours. Scenarios are used to refer to what could plausibly happen rather than deterministically describe what will happen. In this regard, scenarios for the stock [Socio-ecological systems' outcomes] were assumed to evolve exponentially with a fundamental shift in the prevailing systems' structures, exhibiting reinforcing, and balancing feedback loops. Aiming to examine the implications of local and short-term societal actions (i.e., implemented within an individual lifespan) in the long evolutionary behavior of the stock [Social-ecological systems' outcomes], the growth rate for the inflow \{Societal growing action\} was defined as 1.0\%. In this regard, the limiting value of the stock without any limiting factor was gauged as twice its original value (or 100\% accumulated growth) for every 70 years (i.e., the global average lifespan). All applied mathematical relations were defined as linear equations encompassing the stock and the flows with their respective growth rates. Given that the univocal measurement of the social and ecological limiting factors is beyond the scope of this study, all limiting factors were assumed equally important (i.e., with the same weighting factor). To establish a baseline for comparison among the portrayed scenarios, the growth rate variation (as discussed in Section 3.2) was uniformly applied for all net results of the limiting factors. All stock-and-flow diagrams and computer simulations were performed using the modeling software Stella Architect, isee systems (Version 1.9.4).

\section{Results and Discussion}

This section presents the results and discussion regarding the approach proposed to foster long-term and regenerative perspectives on global sustainability, encompassing (i) a critical analysis and synthesis of insights from the fields of systems and resilience thinking, (ii) a conceptual framework for modeling and envisioning socio-ecological systems, and (iii) the proposition of the "flourishing within boundaries" archetype.

\subsection{Modeling and Envisioning Socio-Ecological Systems-A Conceptual Framework}

From an epistemological viewpoint, every knowledge construct is a model. What is referred to as the "real world" is contingent upon how deeply human understanding is able to probe reality. Models are belief systems built as a set of assumptions and explanations aimed at representing and sense making the experienced world [28]. Every model is inevitably influenced by prevailing social perspectives, actions, and goals. Although models are designed to improve understanding of complex relationships and manifest a strong congruence with the experienced world, they fall far short of representing it fully [2,3]. The realism of a model is inherently dependent not on its realistic representativeness, but on its faculty to respond with a coherent pattern of behavior over time [24]. Additionally, isolated systems with well-defined boundaries are conceptual constructs (based on perceptions, logical constructs, and social agreements) and do not exist in the intertwined tissues of the observed world, in which everything comes from somewhere and goes somewhere, and continuously evolves [2].

Model creation and analysis is a highly investigative hands-on activity that fulfills learning by doing. The starting point of socio-ecological system's modeling is divided into the selection and representation of the constituents of the studied systems. The selection of what to include in a model depends concomitantly on how broadly the systems net is cast and how deeply it probes. Models should encompass constituents whose interaction is capable of self-generating the event of interest, filtering out non-essential ones, and distancing from details that jeopardize the examination of patterns and trends. However, it is also important to bear in mind that missing information is one of the most common sources of modeling inaccuracies. The representation of the selected system's 
constituents in the model must be clearly defined in some form of correlational and cause-and-effect logic, acknowledging that coupled social-ecological systems operate through interdependent causality structures [21].

In the prevalent vernacular systems, words in sentences, as well as sentences in texts, come one at a time and are linearly ordered. However, socio-ecological systems are commonly interconnected in many directions at once $[18,21,23,29,30]$. To perform an effective systems analysis, it is crucial to use a language whose lexicon and syntax share some characteristics with the phenomena under consideration. The most widely utilized language in systems studies is the language of stocks-and-flows, in which the systems' structures are described in terms of diagrams of interlocking stock, flows, and feedback loops $[2,3,19,22,24,31]$. The language of stocks and flows is particularly visual and operational, facilitating both mental and computer simulation within multi-, inter-, and transdisciplinary domains. The diagrams contain systems structures depicted in an icon-based lexicon, signifying stock-and-flows models of the observed world [2,32,33].

An essential precept of systems thinking is that there is an inherent interdependence between the system's structure and its functionality $[2,3,19,22,31,34]$. In this regard, systems problems are understood as undesirable patterns of dynamic behavior that emerge from characteristic system structures $[2,3,22]$. In sustainability science, systems thinking is operationalized by examining social-ecological systems, which are modeled as a collection of subsystems along with their self-reinforcing and balancing mechanisms that regulate stock levels by governing physical and informational flows [2,9-12,21-23,35]. In this case, the model is a selective abstraction of the social-ecological system in itself, typically described in terms of storytelling and computer stock-and-flow diagrams [2,3,22]. In this context, Figure 1 depicts a conceptual diagram (storytelling stock-and-flow diagram) for modeling and envisioning socio-ecological systems. It was conceived to provide a set of conceptual tools meant to illuminate long-term and regenerative perspectives on how the socio-ecological systems we are all part of actually operate.

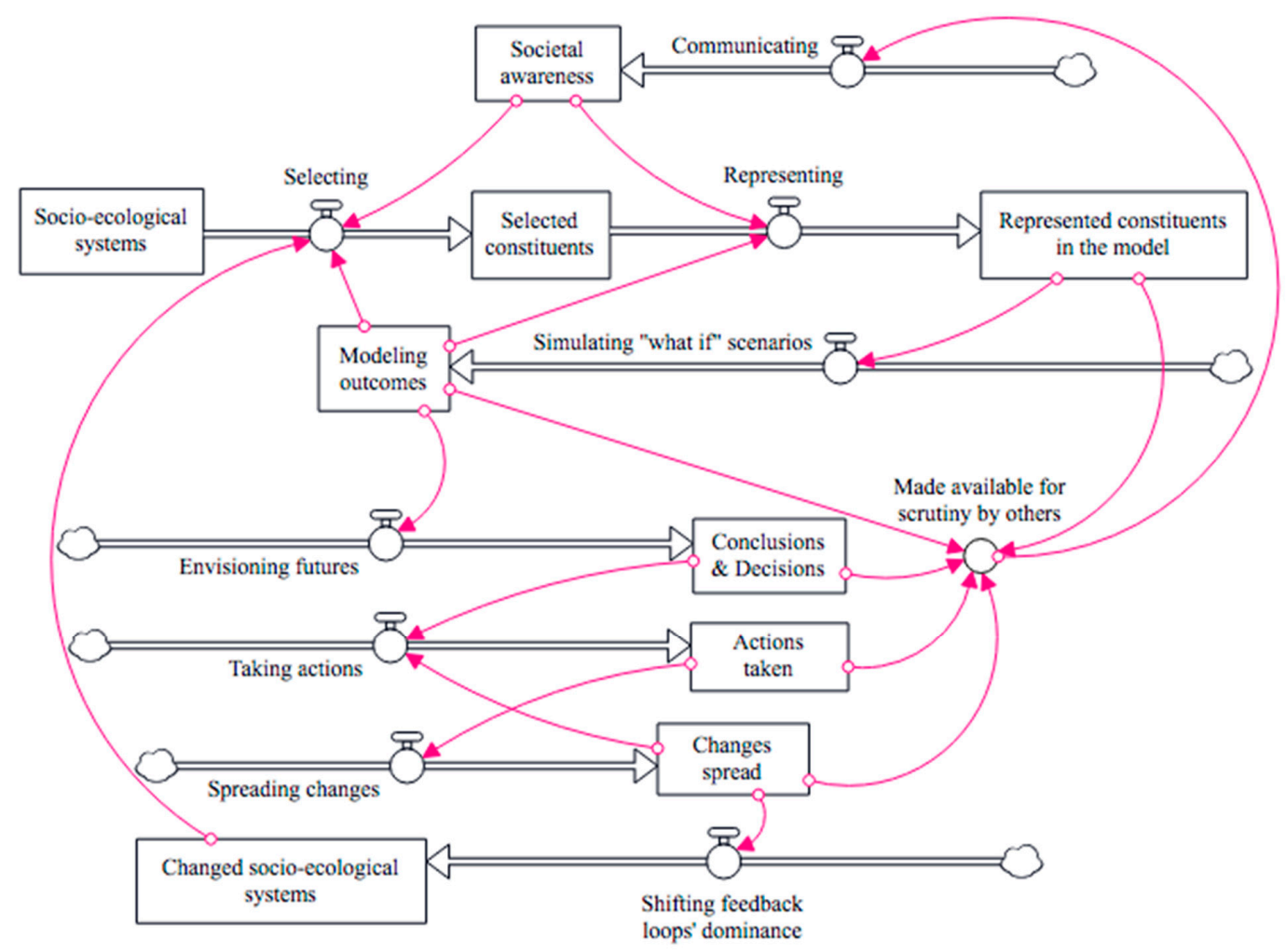

Figure 1. Conceptual diagram for modeling and envisioning socio-ecological systems. 
Both mental and computer simulation play an essential role in modeling and envisioning social-ecological systems. In Figure 1, the connector (illustrated as an arrow)-that runs from the stock [Represented constituents in the model] (represented by a rectangle) to the flow [Simulating "what if" scenarios\} (represented by valves and pipes) indicates that the simulation process can only proceed if a model is designed. Aiming to understand what occurs over time and why, it is necessary to model the interplay of the adopted causal relations under various "what if" scenarios, reviewing the performed assumptions accordingly. Furthermore, the two connectors run from the stock [Modeling outcomes] to the $\{$ Selecting $\}$ and \{Representing\} flows, indicating a feedback loop mechanism of self-reinforcing learning in the model creation. This also indicates that the performed assumptions are inspected for adequacy and improvement in a self-scrutiny circular process.

In light of the obtained modeling outcomes, it is crucial to examine evolutionary patterns of behavior over broad time horizons spatial realms, examining desirable and undesirable scenarios for the future, drawing hypotheses, and defining the best courses for action. Another essential precept of systems thinking is that although the future cannot be predicted, it can be envisioned and brought into being [2,36]. The evolutionary behavior of socio-ecological systems can be envisioned and imaginatively designed and redesigned. However, the more complex the socio-ecological system becomes, the more surprising its dynamic behavior. Socio-ecological systems may exhibit adaptive, transformative, goal-seeking, self-preserving, self-repairing, hierarchical, and balancing and reinforcing evolutionary features $[21,24,27]$. They may also exhibit the property of self-organizing, i.e., the ability to structure themselves, to create new structures, to learn, diversify, and complexify, producing resilience, heterogeneity, and unpredictability [21]. Out of one system, other completely novel systems can emerge. Self-organizing systems develop their own structure and behavior spontaneously without being guided from the top-down [26]. In the process of creating new structures and increasing complexity, self-organizing systems generate dynamic patterns of hierarchy and integration [2,21,29].

Given that acting only when a problem becomes evident may be too late to solve it, the connector that runs from the stock [Modeling outcomes] to the flow [Envisioning futures\} emphasizes that a historical and foresight analysis is a determining element in the decision-making and acting process. Decisions are influenced by a wide variety of factors, including the quality of the information, social values, education, structural means, methods, and personal perspective. As Meadows [2] (p. 167) observed, "Social systems are the external manifestations of cultural thinking patterns and of profound human needs, emotions, strengths, and weaknesses. Changing them is not as simple as saying now all change, or of trusting that he who knows the good shall do the good." Particularly, human's perspective on time and space depends on their culture, their past experiences, their sense of the future, and on the urgency to meet essential needs and resolve problems in their lives. In general, the longer the time horizon and the larger the spatial realm associated with a problem, the shorter the human capacity to perceive it and know the existence of it and, consequently, to think and cope with the demands that arise from it. Broadly, most human perspective is concentrated on short-term issues (e.g., weeks and/or months) related to the closest community (e.g., household, neighborhood), part of it extends slightly farther ahead (e.g., years, life time) into a larger community (e.g., city, states, nations), a smaller part of it extends farther ahead (e.g., ancestors' and next generations' life time) into an even larger community (e.g., planet), and a very small part of it extends far into the long-term past and future of the phenomenon of life, human society, and universe. In this regard, Figure 2 depicts in broad contours the distribution of human perspective over distinctive spatial realms (structured in a qualitative scale varying from household to universe) and time horizons (from now to the past and future of life and human society). In Figure 2, the human perspective is assumed to decay exponentially over longer past and future time horizons and larger spatial realms. To acknowledge the greater unknowability of the future in comparison to the past, increased exponential decay is also assumed, therefore signifying a narrower and shorter human perspective in future time horizons and spatial realms. 


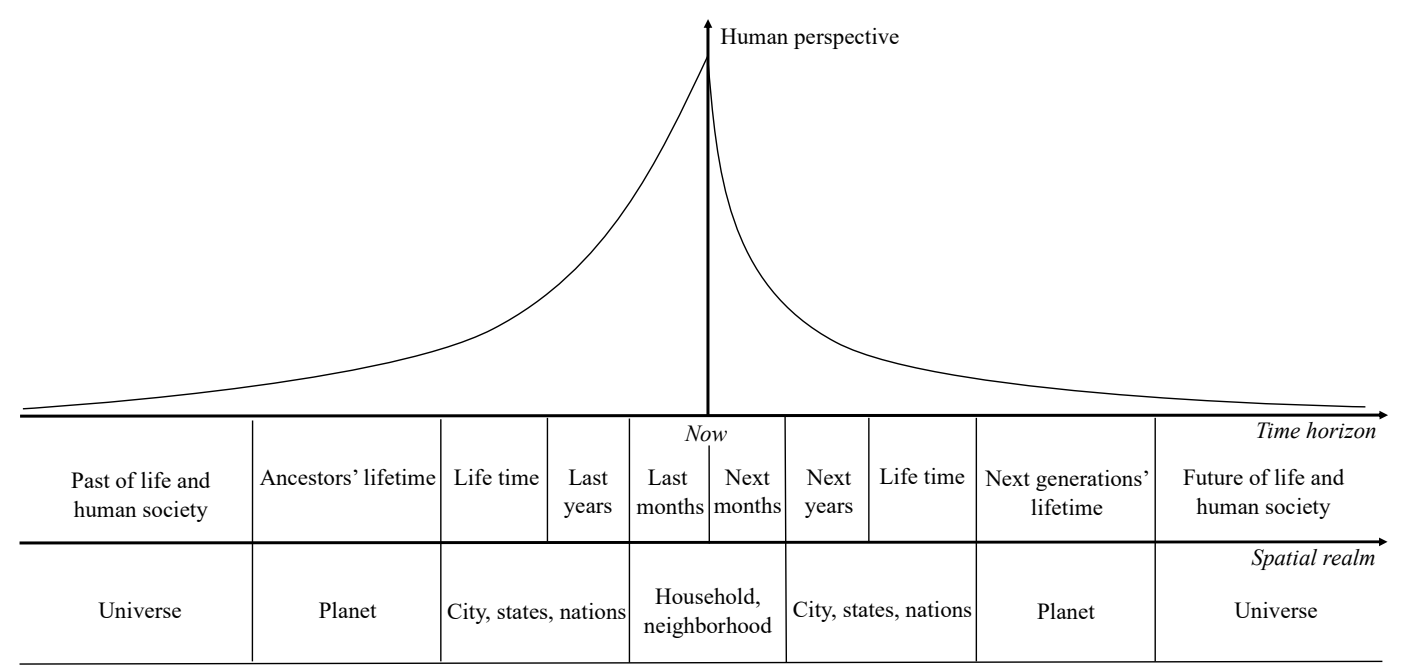

Figure 2. Distribution of human perspective over distinctive spatial realms and time horizons.

Transgressing short-term vision and directing changes to desirable futures requires sensitivity and a robust background in redefining long-term vision and strategies for societal development. In this case, the actions taken must extend not only for days or months, but for years, decades, and centuries into the future. Long-term thinking counteracts the fallacies of narrow-short-term thinking, looking beyond immediate constraints, widening understanding, and offering imaginative ways of addressing unknowability. It also enlightens the ways that actions can be taken, and societal changes spread, nurturing desirable futures and preventing undesirable ones. The process of envisioning long-term dynamic behavior provides key understandings to the underlying socio-ecological systems' structure, which is crucial to the comprehension not just of what is happening but what has been happening, why, how, and for whom. This also gives rise to meaningful engagement, boosting discussions on the nature of undesirable outcomes, and fostering shared insights for desirable ones.

The connector that runs from the stock [Conclusions and decisions] to the flow \{Taking actions\} signifies that accumulated knowledge and meaningful sense of the future are driving forces in the implementation process of actions. It also suggests that actions are mainly taken when there is a rational understanding of and human care for the problem. Societal actions are likely to grow and be disseminated when their cause, cost, and benefits are collectively clear. People typically act when the benefits are timely enough to offset the cost of their actions. In this regard, the connectors that run from the stocks [Actions taken and Changes spread] to the flows \{Spreading changes\} and \{Taking actions\} imply an interdependent relationship between the ways and means that actions are taken and societal changes are spread. The connector that runs from the stock [Changes spread] to the flow \{Shifting feedback loops dominance\} indicates that societal changes are the main raw material in shifting dominant structures of socio-ecological systems. The connector that circles back from the stock [Changed socio-ecological systems] to the flow \{Selecting\} specifies a self-enhancement circling procedure in the modeling design.

Aiming to foster societal awareness and also enhance the modeling construct as a whole, it is crucial to make information available for scrutiny and communicate it accordingly. The connectors that join the variable "Made Available for scrutiny by others" emphasize that the process of communicating boosts societal awareness and control. It generates a common understanding of why a problem persists despite people's best efforts to solve it. By making the information available and communicating it to society, people can reflect on it, question it, learn from it, and act on and spread changes inspired by it. Societal awareness depends on the information provided as well as on people's willingness and ability to perceive it and judge it. Those involved in modeling and envisioning socio-ecological systems make assumptions about what is important to include in the analysis and what is imperative to value from 
it. Finally, what belongs to the system's model is utterly dependent on (and relative to) the systems thinker's perspective and/or conceptual boundaries.

\subsection{Flourishing within Boundaries-A Proposed Archetype}

Out of the myriad of systems categories in the world, archetypes are unique systems structures because they produce distinctive patterns of behavior over time [2]. Archetypes constructs provide building blocks for understanding and sense-making of dynamic behavioral patterns, fostering insights on how systems operate, what makes them produce undesirable results, and how to identify leverage points. Archetypes reveal underlying structures, interactions and interrelationships, enabling the addressal of core issues rather than treating the symptoms. As a result of their capability to represent a wide range of complex problems, for over 40 years archetypes have been well suited towards examining systems in interdisciplinary domains. In particular, playing an important role in sociological debates, the "success to the successful" archetype reveals the underlying drivers of exclusion, unfairness, poverty, monopoly of wealth, and social inequality [2]. Inaugurating a new era in the debate of global environmental issues, the "tragedy of the commons" archetype depicts a circumstance in which individuals pursue actions for their self-interests and benefits, although sharing finite and erodable stocks of natural resources [37]. Notably contributing to the debate on the future of human society at a planetary scale, the "limits to growth" archetype describes the process of quantitative growth in a constrained environment, in which stocks of nonrenewable resources are finite and available at once $[4,38-40]$.

In sustainability science, archetypes structures can be pervasive and destructive, producing persistent and labyrinthine patterns of behaviors over time, commonly called socio-ecological traps, i.e., systems structures in which social and ecological feedback loops mutually reinforce each other and maintain or push social-ecological systems towards undesirable states [41]. A socio-ecological trap can be avoided by recognizing it in advance or by altering the system's structure, goals, and shifting their feedback loops' dominance. Aiming to portray in broad evolutionary contours the pathways in and out of socio-ecological traps as well as understand how socio-ecological systems can be guided towards one pathway or another, Figure 3 depicts (in a stock-and-flow computer diagram) the proposed "flourishing within boundaries" archetype. Taking into consideration the Sustainable Development Goals [6] and Planetary Boundaries Framework [9-12], this proposed archetype, as well as the following scenarios, are modeled to provide meaningful insights regarding the essential conditions that would enable global society to flourish not just safely but also fairly. Acknowledged worldwide as a blueprint to achieve a flourishing future for all, the Sustainable Development Goals are conceived to address essential issues of human society, galvanizing actions at multiple scales for shared and lasting prosperity [6,27,42]. The Planetary Boundaries lays out precautionary thresholds for critical biogeophysical processes that regulate the stability of Earth's life-giving systems. Transgressing one or more planetary boundaries means transgressing the limits of a safe operating space for the development of a flourishing global society, which could prove deleterious, or even catastrophic [9-12].

In Figure 3, the stock [Socio-ecological systems' outcomes] is the accumulation of results over a period of time, signifying the current state of the flows within the socio-ecological system. The flows go into and out from stock, signifying activities that cause conditions to change. In this regard, the inflow \{Societal growing action\} and the outflow \{Societal limiting action\} regulate the stock [Socio-ecological systems' outcomes]. The stock is decreased by decreasing the growth rate of the inflow as well as by increasing the growth rate of the outflow. Therefore, changes in the stock [Socio-ecological systems' outcomes] set the pace of the overall system's dynamics. Given that both flows are not immediate processes, it takes time for the stock to change, thereby acting as a source of momentum and shock absorber. 


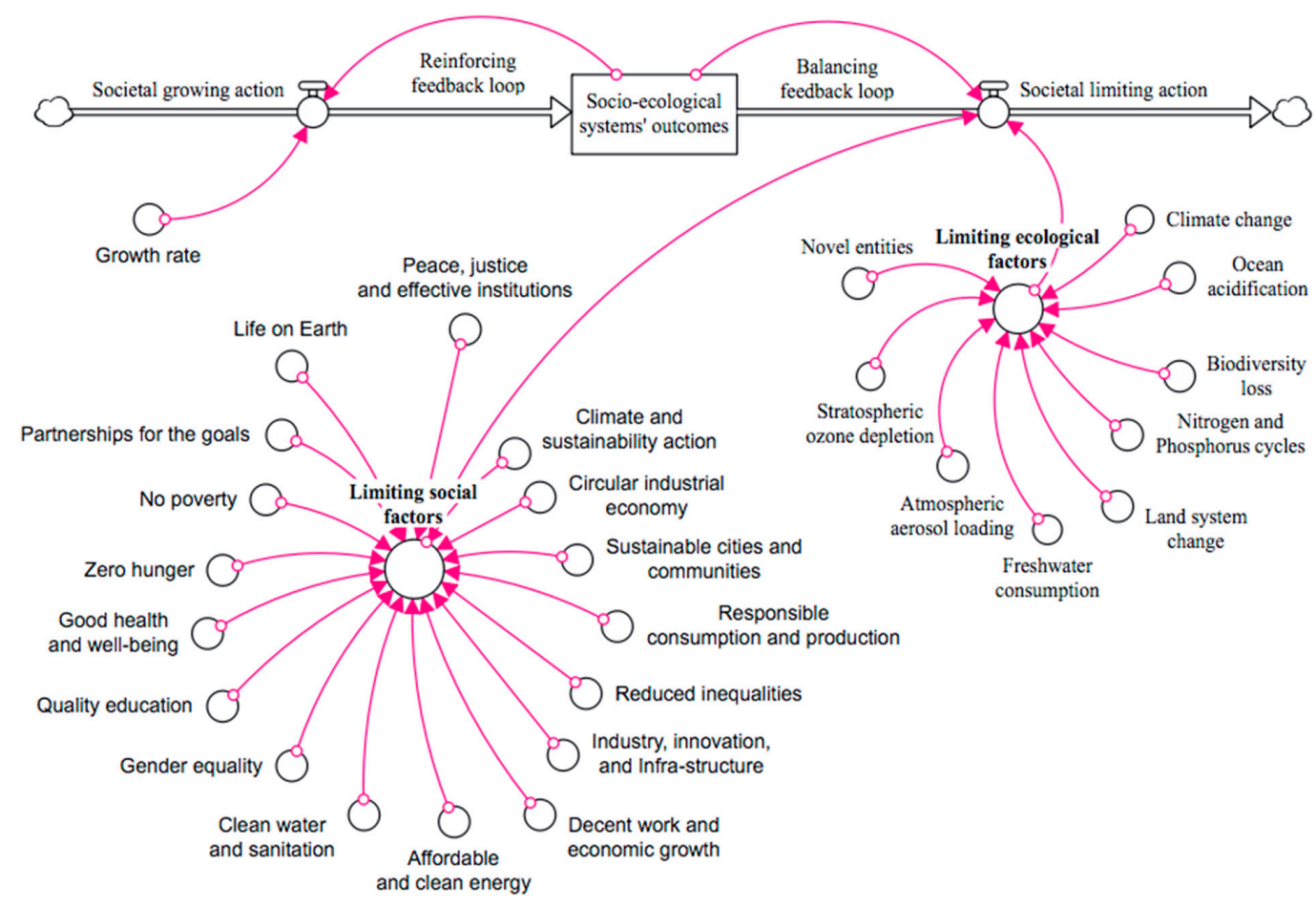

Figure 3. Flourishing within boundaries archetype.

The two connectors that run from the stock to the flows indicate feedback loop mechanisms. In this regard, every societal action triggers a reaction with a feedback loop causality structure that brings results from the past action back to control future actions. The inflow \{Societal growing action\} adds to the stock [Socio-ecological systems' outcomes] that adds to the inflow \{Societal growing action\} in a reinforcing feedback loop mechanism. After some accomplishment in the growing process, this reinforcing mechanism is then offset by an action of a balancing feedback loop. Every feedback loop has its critical threshold, which defines the region in which there is a change from one dynamic regime to another.

Given that physical systems cannot everlastingly grow in a finite environment, self-reinforcing mechanisms must have at least one reinforcing feedback loop-driving the socio-ecological systems' behavior - and one balancing feedback loop-constraining the growth behavior. In this case, the goal-seeking mechanism shifts (either temporarily or permanently) the reinforcing feedback loop dominance either by strengthening the outflow or by weakening the inflow. Furthermore, feedback loops give rise to nonlinear behavior, even if all constituent causal relationships are linear. Nonlinearities in feedback loops change their relative strengths, shifting dominance of self-reinforcing or goal-seeking mechanisms. While the reinforcing mechanism is operating, the stock interacts with "Limiting social factors" and "Limiting ecological factors", that add to the outflow \{Societal limiting action\}. These limiting factors are defined in alignment with the existing 17 Sustainable Development Goals and 9 Planetary Boundaries. Finally, systems boundaries are represented by clouds on the flows and are purpose-problem-dependent, delimited by spatial and temporal thresholds.

The proposed "flourishing within boundaries" archetype is modeled to allow the scrutiny of essential direction-setters of the system's evolutionary behavior, indicating circumstances that require societal actions, and signaling failure or success toward a desirable state and feedback loop dominance. Aiming to envision the long-term implications of distinctive values of growth rate for the inflow \{Societal growing actions\} and for the outflow \{Societal limiting actions\} in the evolutionary behavior of the stock [Social-ecological systems' outcomes], Figure 4 depicts the simulation results for a set of scenarios within the time frame of 500 years (labeled from S0 to S7). 


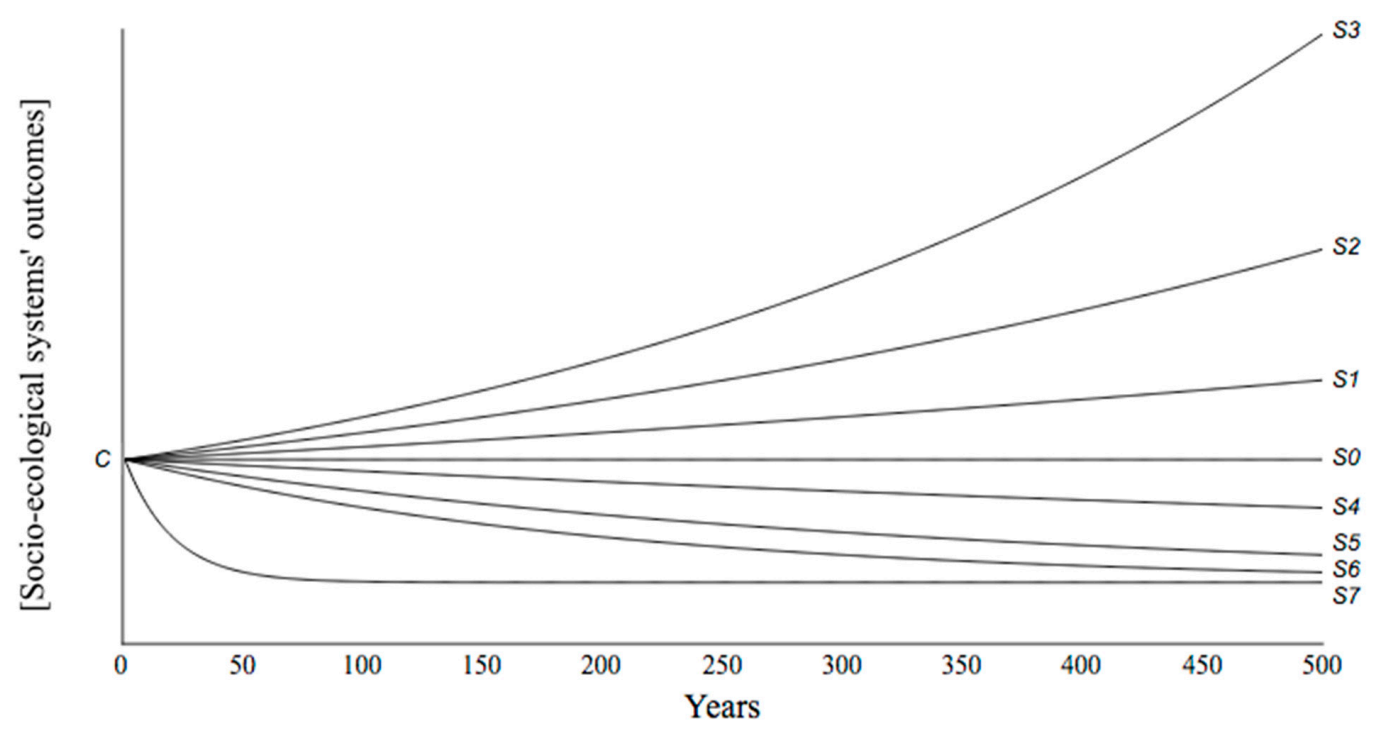

Figure 4. Scenarios (labeled from S0 to S7) for the evolutionary behavior of the stock [Social-ecological systems' outcomes].

In Figure 4, fixed in an arbitrary value, the parameter $C$ denotes the current state of the flows within the system. In $S 0$, the growth rate for the inflow and outflow are equal. As expected for this baseline scenario, no transition is identified in the evolutionary behavior of the stock, indicating that the reinforcing feedback loop associated with the flow of societal actions is consistently offset by the balancing feedback loop that arises from the net results of the social and ecological limiting factors. In $S 1, S 2$, and $S 3$, the growth rates for the inflow are, respectively, $1.0 \%, 3.0 \%$, and $4.0 \%$ higher than the growth rates for the outflow. In these scenarios, the higher the growth rate for the inflow the greater the pace of the system towards higher values of the stock. In $S 4, S 5, S 6$, and $S 7$, the growth rates for the outflow are, respectively, $1.0 \%, 3.0 \%, 4.0 \%$, and $50.0 \%$ higher than the growth rates for the inflow. Conversely, in these scenarios the higher the growth rate for the outflow the greater the pace of the system towards lower values of the stock.

The flourishing patterns of behavior over time portrayed in the scenarios $S 1, S 2$, and $S 3$ are characterized by persistent actions towards increasing values of the stock [socio-ecological systems' outcomes]. In this regard, the direction-setters of the system's evolutionary behavior are the promising pace of the inflow, the degree of achievement of positive outcomes within boundaries, and the societal ability to identify leverage points in order to intervene in socio-ecological structures. In these scenarios, the socio-ecological systems are understood as highly regenerative and resilient. Societies are proactively committed to sustainability and enlightened by meaningful aspirations, such as solidarity, dignity, fairness, quality of life, collective consciousness, synergistic connection with nature, ecological sensibility and responsibility, and integral ecological worldview.

By contrast, the scenarios $S 4, S 5, S 6$, and $S 7$ are characterized by traps and collapsing mechanisms, in which the net results of the limiting factors go beyond critical thresholds, continuously decreasing the values of the stock. In this regard, the main direction-setters of the system's evolutionary behavior are the alarming pace of the outflow, the narrow range of the critical thresholds associated with Earth's planetary boundaries, and the societal difficulty to achieve the Sustainable Development Goals. Given the self-reinforcing mechanisms associated with both limiting factors, the more thresholds are transgressed, the less the socio-ecological systems are able to adapt and regenerate themselves, or the more likely they are to collapse. In these scenarios, the socio-ecological systems are neither resilient nor sufficiently regenerative. Societies are highly dysfunctional and evolve with a growing risk of calamitous disruptions, including major threatening events, an abrupt decline of Earth's life-giving systems, and civilizational failure. 
As observed in Figure 4, all portrayed scenarios exhibit an exponential behavior over time. However, the pace of the transitions associated with the reinforcing feedback loop dominance (i.e., scenarios S1, S2, and S3) is notably higher over time than the ones associated with the balancing feedback loop dominance (i.e., S4, S5, S6, and S7). Aiming to illustrate this important feature, Figure 5 depicts the comparative results for $S 1$ (black color), S2 (very dark grey), S3 (dark grey), S4 (grey), S5 (light grey), and S6 (very light grey).

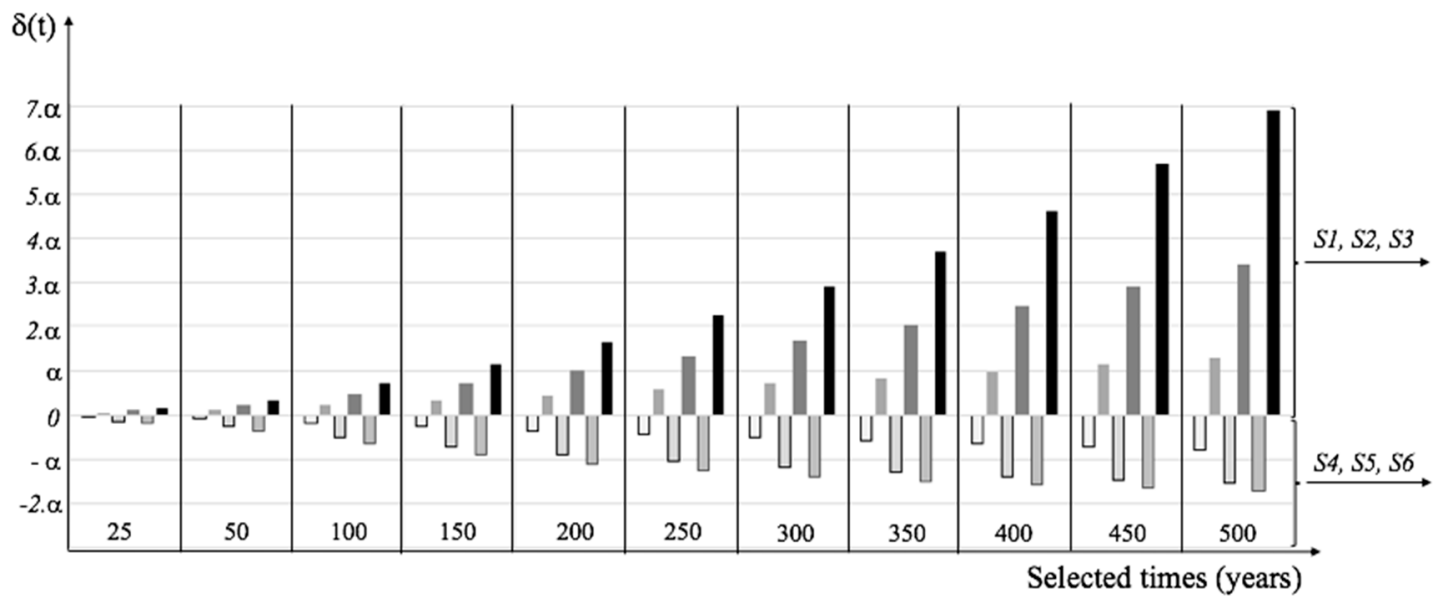

Figure 5. Variation in the value of the stock [Socio-ecological systems' outcomes] for the portrayed scenarios S1 (black color), S2 (very dark grey), S3 (dark grey), S4 (grey), S5 (light grey), and S6 (very light grey).

In Figure 5, the variable $\delta(t)$ is the variation in the value of the stock [Socio-ecological systems' outcomes] in relation to the stock value of $S 0$. Structured on a comparative scale, the value of $\delta(t)$ is assessed at selected times and expressed in terms of the proportionality factor $\alpha$. The ratios between $\delta(t)_{S 1, S 2, S 3}$ and their counterparts $\delta(t)_{S 4, S 5, S 6}$, are, respectively, 1.03, 0.71, and 0.82 for $t=25.0$ years, and 1.65, 2.21, and 4.01 for $t=500.0$ years. Particularly, $\delta(t)_{S 1}$ is invariably higher than its counterpart $\delta(t)_{S 4}$, signifying that the reinforcing feedback loop is consistently dominant. Nevertheless, $\delta(t)_{S 2}$ and $\delta(t)_{S 3}$ are only higher than their counterparts $\delta(t)_{S 5}$ and $\delta(t)_{S 6}$ from the time horizons of 165.0 years and 84.0 years, respectively, specifying that up to these times the balancing feedback loop is dominant. Therefore, the reinforcing feedback loop associated with the inflow \{Societal growing actions\} adds to the stock in a gradual upward process, increasingly offsetting the balancing feedback loop that arises from net results of both limiting factors. In this regard, the speed of the threats dictates the required growth rate of societal actions. Given that both flows and feedback loop mechanisms are not immediate processes, it takes time for the stock to change. Actions taken by individuals in the local realm and short-term time horizon may not only have immediate local effects but also a variety of innumerous ones that radiate out for years, decades, and even centuries to come. However, varying the length of delays significantly alter the socio-ecological systems' responses to change, including how timely changes are transmitted within the socio-ecological systems. Particularly, a delayed response regarding the disruption of the Earth's life-giving systems is highly risky of being too late to prevent serious damage at a planetary scale.

\section{Additional Remarks-Furthering a Culture of Long-Term Thinking and Regenerative Change}

According to the basic laws of physics, there will always be boundaries to quantitative growth in constrained systems. The prosperous choice for human society is not to grow inadvertently and irresponsibly, but to self-impose its own precautionary thresholds to flourish within the capacity of the Earth's life-giving systems. Flourishing within boundaries is a radical and collective concept that requires multi-scaled participation within societal structures and depends on connecting, restoring, and sharing several forms of resources. In this regard, it is crucial to foster a culture of long-term thinking 
and regenerative change by intention and design, nurturing holistic ways of thinking and acting in real-life settings, and boosting collaboration into every human interaction and every intervention in the physical world.

Long-term thinking and regenerative change cannot be achieved without iterative and integrative actions from individuals, households, markets, and societies. Community creates the conditions in which each individual may flourish. Relationships are essential resources located at the heart of flourishing societies [43]. Actions occur when an individual(s) feel supported by strong relationships that further their capabilities, including a sense of possibility, learning faculties, empowerment, and fulfillment. They are also likely to emerge when a vision that brings hope for a desirable future is acknowledged, magnifying the sense of being part of and contributing to a collective purpose for the future. The more relationships and diversity in social networks, the stronger the solutions, thus increasing collaboration towards new ways of seeing, listening, communicating, acting, and caring. Diverse systems with multiple interactions, redundancies, and pathways are more resilient (i.e., persistent, adaptable, and transformative) than uniform systems with little diversity. Furthermore, no part of the human race is disconnected from Earth's life-giving systems. The ultimate community is the planet Earth within the universe. Good lives are not possible without a healthy planet. For change to be regenerative, it must be guided by an integral worldview inspired by nature as a whole, cooperating with it, participating in its processes, and learning from it. Even though the dominant mindsets are more enticed by straight lines and not curves, uniformity and not diversity, whole forms and not fractals, convictions and not uncertainty, the complexity of nature and its non-linear behavior must be acknowledged and celebrated.

Change comes first with transcending paradigms and mindsets out of which the systems structures arise. Information is an essential resource and must be accurate and timely available. It is vitally important to step out of any inaccurate and limited informational realm in the system, expanding the boundary of human care, and ensuring a long-term perspective. To cope with complex problems, it is crucial to understand events as part of trends and trends as symptoms of underlying systems structures $[2,3,22]$. While doing so, it is necessary to step back from events in order to identify behavioral patterns over long-time horizons and spatial realms, recognizing what structure contain which behavior, and classifying destructive and beneficial interactions. Achieving regenerative change requires effective scrutiny of the socio-ecological system's structure and leverage points in order to understand places in which a small change could lead to a large shift in the system's prevailing structures. However, there is no single solution for a complex problem and a typical socio-ecological system has a large variety of intricate leverage points [2].

The longer the operant time horizon (i.e., the period of time in which actions, impacts, costs, and benefits are evaluated), the better the chances for survival and flourishment. Nevertheless, as previously discussed, excessive attention is dedicated to local and current events, disregarding large scale and long-term ones. The operant time horizons have not been extended much beyond one generation or even beyond the period of current financial investments. Narrow and short-term thinking are common characteristics of bounded rationality that leads to societal dysfunction and failure. Individuals, like societies, commonly underestimate, ignore, and deny complex issues until an undesirable tipping point is triggered by a major event. Historical evidence suggests that societies that have lost their identity with ancestry and posterity and, therefore, with past lessons and visions of the future, lost also their capacity to address essential issues in the present [44-46].

Long-term thinking is crucial to the comprehension not just of what is happening, but what has been happening, why, how, and especially for whom. The concept of flourishing within boundaries is inextricably linked to inequality. Surprisingly, only a small portion of the world's population is not operating within planetary boundaries. Inequality makes societies dysfunctional across a wide range of socio-ecological outcomes. Extreme lifestyles with operating rates that make little ecological sense have been consistently adopted and made role models and standards. Particular to climate change, the poorest $50.0 \%$ of the world's population ( $\cong 3.8$ billion people) are responsible for only 
around $10.0 \%$ of total global GHG emissions attributed to individual consumption [47]. By contrast, the richest $10.0 \%$ emit about $50.0 \%$ of total global GHG emission, and the richest $1.0 \%$ emit more than the poorest $50.0 \%$ [47]. Strikingly, the average carbon footprint of an individual in the richest $1.0 \%$ is around 175 times greater than an individual in the poorest $10.0 \%$ [47]. Furthermore, about $11.0 \%$ of the world's population suffers from hunger and survive below the poverty line with very little to no work opportunities, $16.0 \%$ lack access to electricity, $10.0 \%$ lack education [6], and 30.0\% reside in urban slums [48]. Globally, societies with higher equality are in a better position to cope with global sustainability issues, exhibiting lower carbon and ecological footprints, producing less waste, consuming less water, and flying less per capita [49]. More equal societies foster a greater sense of collaboration and intergenerational responsibility, which is essential for furthering a culture of long-term thinking and regenerative change.

\section{Conclusions}

This study is conceived to embody key issues and debates on global sustainability as well as insights from the field of systems and resilience thinking. The proposed conceptual framework (Section 3.1) presents a guiding tool for modeling and envisioning socio-ecological systems and their patterns of behavior over time. Taking into consideration the Sustainable Development Goals and Planetary Boundaries Framework, the proposed "flourishing within boundaries" archetype (Section 3.2) provides meaningful insights regarding the essential conditions that would enable global society to flourish not just safely but also fairly. Given the ever-shifting nature inherently associated with global sustainability and socio-ecological systems, it is also designed to present an adaptable and scalable solution, thereby offering a touchstone for further improvements. Portrayed scenarios emphasize that the higher the regenerative societal change achieved, the greater the exponential behavior of the system's speed towards promising socio-ecological outcomes. Especially for longer time horizons, the overall results reveal that the pace of the transitions associated with the societal action is inherently higher than those associated with the limiting social and ecological factors. Actions taken by individuals in the local realm and short-term time horizon may not only have immediate local effects but also a variety of innumerous ones that radiate out for years, decades, and even centuries to come. Systems and long-term thinking are complementary and revealing. Systems thinking leads human knowledge to the edges of what rational analysis can do and long-term thinking points beyond, casting imagination towards the realm of the unknown. Futuristic knowing is not just the understanding of the world. It is a view of life and its interdependence with Earth's giving systems. It is also a collective aspiration to thrive as a society in a world filled with mystery, meaning, awe, and fear. Finally, the pursuit of flourishing within boundaries relies on thinking rationally, globally, and above all, through a long-term and regenerative perspective.

Funding: This research received no external funding.

Acknowledgments: The author would like to acknowledge the Interdisciplinary Center for the Unknown (ICU) fostering global sustainability through imagination and futures studies for the financial support associated with the open access publication of this article and to Laura M. Gustavson for the comments on this manuscript.

Conflicts of Interest: The author declares no conflict of interest.

\section{References}

1. Morin, E. La Méthode 2: La vie de la vie; Éditions du Seuil: Paris, France, 1980; pp. 1-482.

2. Meadows, H.D. Thinking in Systems: A Primer; Wright, D., Ed.; Sustainability Institute, Chelsea Green Publishing: White River Junction, VT, USA, 2008; pp. 1-218.

3. Forrester, J.W. Industrial Dynamics; The MIT Press: Cambridge, MA, USA, 1961; pp. 1-464.

4. Meadows, H.D.; Randers, J.; Meadows, D. Limits to Growth: The 30-Year Update; Chelsea Green Publishing: White River Junction, VT, USA, 2004; pp. 1-368.

5. Raworth, K. Doughnut Economics -7 Ways to Think Like a 21st Century Economist; Chelsea Green Publishing: Vermont, VT, USA, 2017; pp. 1-309. 
6. United Nations Department of Economic and Social Affairs. The Sustainable Development Goals Report; United Nations Department of Economic and Social Affairs: New York, NY, USA, 2018.

7. Willamo, R.; Helenius, L.; Holmstrom, C.; Haapanen, L.; Sandström, V.; Huotari, E.; Kaarre, K.; Värre, U.; Nuotiomäki, A.; Happonen, J.; et al. Learning how to understand complexity and deal with sustainability challenges-A framework for a comprehensive approach and its application in university education. Ecol. Model. 2018, 370, 1-13. [CrossRef]

8. Bastianonia, S.; Coscieme, L.; Caro, D.; Marchettini, N.; Pulselli, F.M. The needs of sustainability: The overarching contribution of systems approach. Ecol. Indic. 2019, 100, 69-73. [CrossRef]

9. Rockstrom, J.; Steffen, W.; Noone, K.; Persson, Å.; Chapin, F.S.; Lambin, E.F.; Lenton, T.M.; Scheffer, M.; Folke, C.; Schellnhuber, H.J.; et al. A safe operating space for humanity. Nature 2009, 461, 472-475. [CrossRef] [PubMed]

10. Rockström, J.; Klum, M. Big World, Small Planet-Abundance within Planetary Boundaries; Yale University Press: New Haven, CT, USA, 2015; pp. 1-206.

11. Steffen, W.; Persson, Å.; Deutsch, L.; Zalasiewicz, J.; Williams, M.; Richardson, K.; Crumley, C.; Crutzen, P.; Folke, C.; Gordon, L.; et al. The Anthropocene: From Global Change to Planetary Stewardship. Ambio 2011, 40, 739-761. [CrossRef]

12. Steffen, W.; Richardson, K.; Rockström, J.; Cornell, S.E.; Fetzer, I.; Bennett, E.M.; Biggs, R.; Carpenter, S.R.; de Vries, W.; de Wit, C.A.; et al. Planetary Boundaries: Guiding human development on a changing planet. Science 2015, 347, 6223. [CrossRef]

13. Intergovernmental Panel on Climate Change. Climate Change 2014: Synthesis Report, 2015. Available online: http://www.ipcc.ch/pdf/assessment-report/ar5/syr/SYR_AR5_FINAL_full_wcover.pdf (accessed on 25 September 2018).

14. Lewis, E. Intergovernmental Panel on Climate Change. Sustainaspeak 2018, 153-154.

15. Piketty, T. Capital in the Twenty-First Century; Harvard University Press: Cambridge, MA, USA, 2014; pp. 237-270.

16. Slaughter, R.A. Welcome to the Anthropocene. Future 2012, 44, 119-126. [CrossRef]

17. Breyer, C.; Heinonen, S.; Ruotsalainen, J. New consciousness: A societal and energetic vision for rebalancing humankind within the limits of planet Earth. Technol. Forecast. Soc. Chang. 2017, 114, 7-15. [CrossRef]

18. Rogers, K.H.; Luton, R.; Biggs, H.; Biggs, R.; Blignaut, S.; Choles, A.G.; Palmer, C.G.; Tangwe, P. Fostering complexity thinking in action research for change in social-ecological systems. Ecol. Soc. 2013, 18, 31. [CrossRef]

19. Forrester, J.W. Industrial dynamics-after the first decade. Manag. Sci. 1968, 14, 398-415. [CrossRef]

20. Fisk, D.; Kerhervé, J. Complexity as a cause of unsustainability. Ecol. Complex. 2006, 3, 336-343. [CrossRef]

21. Cumming, G.S.; Peterson, G.D. Unifying research on social-ecological resilience and collapse. Trends Ecol. Evol. 2017, 32, 695-713. [CrossRef]

22. Forrester, J.W. World Dynamics, 2nd ed.; Wright-Allen Press: Cambridge, MA, USA, 1973; pp. 1-464.

23. Berkes, F.; Colding, J.; Folke, C. Navigating Social-Ecological Systems: Building Resilience for Complexity and Change; Cambridge University Press: Cambridge, UK, 2003; pp. 1-388.

24. Meadows, H.D.; Robinson, J.M. The Electronic Oracle: Computer Models and Social Decisions; System Dynamics Society: New York, NY, USA, 2007; pp. 1-439.

25. Helfgott, A. Operationalising systemic resilience. Eur. J. Oper. Res. 2018, 268, 852-864. [CrossRef]

26. Williams, A.; Kennedy, S.; Philipp, F.; Whiteman, G. Systems thinking: A review of sustainability management research. J. Clean. Prod. 2017, 148, 866-881. [CrossRef]

27. Casarejos, F.; Da Rocha, J.F.V. Envisioning societal achievement and legacy of intergenerational yield vis-à-vis essential precepts for sustainability and stability of Earth's life-giving systems. Future 2019, 105, 91-103. [CrossRef]

28. Einstein, A. On the Method of Theoretical Physics. Philos. Sci. 1934, 1, 163-169. [CrossRef]

29. Galaz, V.; Crona, B.; Österblom, H.; Olsson, P.; Folke, C. Polycentric systems and interacting planetary boundaries-Emerging governance of climate change-ocean acidification-marine biodiversity. Ecol. Econ. 2012, 81, 21-32. [CrossRef]

30. Saritas, O.; Nugroho, Y. Mapping issues and envisaging futures: An evolutionary scenario approach. Technol. Forecast. Soc. Chang. 2012, 79, 509-529. [CrossRef]

31. Forrester, J.W. Urban Dynamics; The MIT Press: Cambridge, MA, USA, 1969; pp. 1-290. 
32. Pruyt, E. Small System Dynamics Models for Big Issues: Triple Jump towards Real-World Complexity; TU Delft Library: Delft, The Netherlands, 2013; pp. 1-324.

33. Nabavi, E.; Daniell, K.A.; Najafi, H. Boundary matters: The potential of system dynamics to support sustainability? J. Clean. Prod. 2017, 140, 312-323. [CrossRef]

34. Churchman, C.W. The Systems Approach; Delacorte Press: New York, NY, USA, 1968; pp. 1-243.

35. Filatova, T.; Polhill, J.G.; van Ewijk, S. Regime shifts in coupled socio-environmental systems: Review of modelling challenges and approaches. Environ. Model. Softw. 2016, 75, 333-347. [CrossRef]

36. Raskin, P. Journey to Earthland-The Great Transition to Planetary Civilization; Tellus Institute: Boston, MA, USA, 2016; pp. 1-69.

37. Hardin, G. The Tragedy of the Commons. Science 1968, 162, 1243-1248. [PubMed]

38. Meadows, D.H.; Meadows, D.L.; Randers, J.; Behrens, W.W., III. The Limits to Growth; Universe Books: New York, NY, USA, 1972; pp. 1-205.

39. Meadows, D.H.; Meadows, D.L.; Randers, J.; Behrens, W.W. A response to Sussex. Future 1973, 5, $135-152$. [CrossRef]

40. Meadows, H.D.; Meadows, D.; Randers, J. Beyond the Limits: Confronting Global Collapse, Envisioning a Sustainable Future; Chelsea Green Publishing: Post Mills, VT, USA, 1992; pp. 1-300.

41. Stockholm Resilience Centre. Interaction between Social and Ecological Feedbacks Can Lock Systems into Unsustainable Pathways, Creating Social-Ecological Traps, 2019. Available online: https://www.stockholmresilience.org/download/18.3e9bddec1373daf16fa43c/1459560363484/INsights_ Social-ecological\%20traps_111108-2.pdf (accessed on 2 May 2019).

42. Hajer, M.; Nilsson, M.; Raworth, K.; Bakker, P.; Berkhout, F.; De Boer, Y.; Rockström, J.; Ludwig, K.; Kok, M. Beyond Cockpit-ism: Four Insights to Enhance the Transformative Potential of the Sustainable Development Goals. Sustainability 2015, 7, 1651-1660. [CrossRef]

43. Cottam, H. Radical Help-How We Can Remake the Relationships between Us and Revolutionize the Welfare State; Virago Press: London, UK, 2019; pp. 1-308.

44. Diamond, L. Collapse-How Societies Choose to Fail or Succeed; Penguin Books: New York, NY, USA, 2011; pp. 1-590.

45. Diamond, L. The World Until Yesterday-What Can We Learn from Traditional Societies? Penguin Books: New York, NY, USA, 2012; pp. 1-444.

46. Acemoglu, D.; Robinson, J.A. Why Nations Fail-the Origins of Power, Prosperity, and Poverty; Currency Press: New York, NY, USA, 2012; pp. 1-529.

47. Oxfam. Extreme Carbon Inequality-Why the Paris Climate Deal Must Put the Poorest, Lowest Emitting and Most Vulnerable People First, 2015. Available online: https://www-cdn.oxfam.org/s3fs-public/file_ attachments/mb-extreme-carbon-inequality-021215-en.pdf (accessed on 29 July 2019).

48. World Bank. Population Living in Slums (\% of Urban Population), 2014. Available online: https://data.worldbank. org/indicator/EN.POP.SLUM.UR.ZS (accessed on 28 July 2019).

49. Wilkinson, R.; Pickett, K. The Spirit Level-Why Greater Equality Makes Societies Stronger; Bloomsbury Press: New York, NY, USA, 2010; pp. 1-343.

(C) 2020 by the author. Licensee MDPI, Basel, Switzerland. This article is an open access article distributed under the terms and conditions of the Creative Commons Attribution (CC BY) license (http://creativecommons.org/licenses/by/4.0/). 